\title{
Cultural Knowledge Management of the Great Tradition: A Case Study of Royal Traditional Thai Crafts School for Men
}

\author{
Chaloempond Chantong \\ 2 Prachan Rd., Prabarommaharachawang, Pranakorn, Bangkok, Thailand \\ Program of Management of Cultural Heritage and Creative Industries
}

\begin{abstract}
The objectives of the study were: (1) To study cultural knowledge management of the Great Tradition (Bureaucrat's way of life) at Royal Traditional Thai school for Men, and (2) to study the changes and adaptation of itself. This focuses on the curriculum of Classical Thai Arts such as mural painting, stucco, fresco, mother-ofpearl inlay, classical music, etc. They were analyzed according to the information sources, concepts and theories about knowledge management and cultural management.

The findings indicated that the knowledge management of this school spread Great Tradition to Little Tradition (Peasant's way of life). The school had changed some curriculum up-to-date but they still followed the Great tradition. However, materials management could be changed and easy to find in the general markets but their quality must be the same.
\end{abstract}

Keywords: Knowledge Management, Intangible Cultural Heritage, Great Tradition

\section{Introduction}

Culture is everything that man made. It is required by all humans through enculturation. Culture encompasses ruled share symbol-based learned behavior and believes transmitted across the generation. Socially and officially there are 2 kinds of culture in Thailand. Social Scientists are likely to separate between great tradition (Bureaucrat's way of life) and little tradition (Peasant's way of life). Great tradition is a culture of nobility. By and large, great tradition is the main source of national culture. Almost of classical Thai arts such as mural painting, stucco, fresco, mother-of-pearl inlay, traditional music, etc. have been originated from royal before being wide-spread nationwide.

Nowadays, the study of Thai arts has many kinds to engage, but each art has itself characteristic and diversity of glamour. The Royal Traditional Thai Crafts School for Men is a school that provides the royal traditional Arts and some royal rites to Thai people who would like to engage the taste of royal traditional Thai arts. This school is the royal project initiated by Her Royal Highness Princess Maha Chakri Sirindhorn that she would like to restore Wat Phra Si Rattana Satsadaram (Temple of the Emerald Buddha) and the Grand Palace in the cerebration of 200 years anniversary of Rattanakosin in 1982 (2525B.E.). The restoration found that there was lack of professional craftsmen so the princess would have the school for practicing Thai adults who were interested in Chang Sip Mu (Thai Ten Crafts). This school has been permitted since 1988 (2531B.E.) at Utestaksina Building in the Grand Palace compound was used as the school building.

The objectives of the study were to study cultural knowledge management of great tradition at Royal Traditional Thai school for Men, and to study the changes and adaptation of itself. This focuses on the curriculum of classical Thai arts such as mural painting, stucco, fresco, mother-of-pearl inlay, traditional music, etc.

\section{The Study of this research}

\subsection{Documentaries}

This part is studying about Knowledge Management, Safeguarding of Intangible Heritage, Chang Sip Mu (literally translated as ten skilled craftsmanship) and Curriculum of Royal Traditional Thai Crafts School for Male. 
Knowledge from Cambridge Dictionary (online) is a noun that means "understanding of or information about a subject that you get by experience or study, either known by one person or by people generally". Oxford Dictionary (online) is "Facts, information, and skills acquired through experience or education; the theoretical or practical understanding of a subject" so I can see that those dictionaries tried to explain that the understanding of the information through experience in both of theoretical or practical.

Knowledge Management (Koenig, 2012) is organizing and organization's information and knowledge holistically so it is the process of capturing, distributing and effectively using knowledge. There are 2 kinds of knowledge (Polanyi and Nonaka, 1998). Firstly, Tacit Knowledge that is the knowledge within the human. It can gain by their experiences and talents and they will present by tangible and/or intangible forms and this can share to the others. Secondly, Explicit Knowledge that is reasonable and can present only tangible forms such as books, manuals, documents and reports. If we compare tacit knowledge and explicit knowledge, we will find that we have more tacit knowledge than explicit knowledge about 80:20. This is similar to the flooding of iceberg on the ocean that we can see the top is flooding about $20 \%$ as shown in fig. 1.

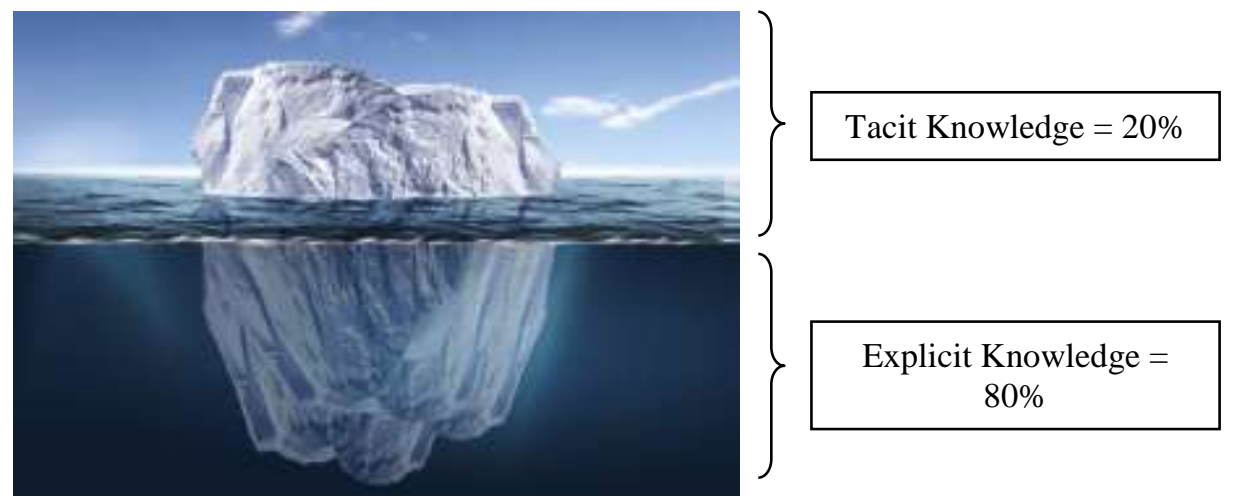

Fig. 1: "Iceberg compares to tacit knowledge and explicit knowledge"

From Fig. 1 can know that the amount of explicit is more than the amount of tacit so that is easy to engage but it will transform people to people by the knowledge transmission that is studying. Both of these knowledge can change their statuses. The main factor that makes them changing is the situation that creates new knowledge by the process of Knowledge Spiral or SECI Model was created by Ikujiro Nonaka and Takeuchi as displayed in Fig. 2.

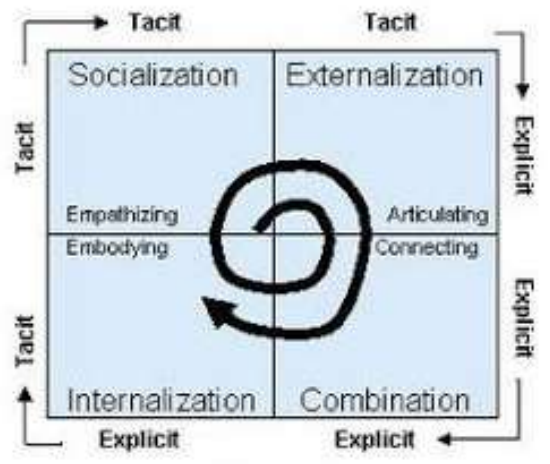

Source: Nonaka and Takeuchi (1999)

Fig. 2: "SECI Model"

Fig. 2 explains about the transmission and creation of knowledge that will be in 4 forms:

1. Socialization is the process to transmit the knowledge from person to person directly by chatting or working together.

2. Externalization is a creation and sharing their knowledge or experience in literacy so they are books, documents and reports.

3. Internalization is to exchange or share new knowledge with doing practically.

4. Combination is from knowledge exchanging by practicing systematically and creating innovations. 
The knowledge management (Nerngchamnong, 2014) has 6 processes that are identifying, creating, exchanging, collecting, using and accessing.

Cultural heritage can be classified as both tangible cultural heritage and intangible cultural heritage. Intangible Cultural Heritage is more concerning as found in the CONVENTION FOR THE SAFEGUARDING OF THE INTANGIBLE CULTURAL HERITAGE of UNESCO on 17 October 2003 at Paris, France. It showed on the Article 2 - Definitions that it is the practices, representations, expressions, knowledge, skills - as well as the instruments, objects, artifacts and cultural spaces associated therewith - that communities, groups and in some cases, individuals recognize as part of their cultural heritage. The UNESCO also gave the definitions of the Intangible The cultural heritage can be classified 5 domains. Intangible Cultural Heritage of the Department of Cultural Promotion, Ministry of Culture gave the definition to be 7 mains that will show at the table below.

TABLE: A Comparison of Intangible Cultural Heritage between UNESCO and Ministry of Culture

\begin{tabular}{ll}
\hline \hline UNESO & Ministry of Culture \\
\hline (1) Oral traditions and expressions, including & (1) Folk Literature \\
language as a vehicle of the intangible cultural & (2) Local and Ethnic languages \\
heritage & (3) Performing Arts \\
(2) Performing arts; & (4) Folk sports, games and martial arts \\
(3) Social practices, rituals and festive events & (5) Social Practices, rituals and festive \\
(4) Knowledge and practices concerning nature & events \\
and the universe & (6) Knowledge and practices \\
(5) Traditional craftsmanship & concerning nature and the universe \\
\end{tabular}

As shown in the above table, Thai Ministry of Culture has also been concerning about Intangible Cultural Heritage. The safeguarding has also appeared in this UNESCO convention that it gave the meanings to be the measures that aimed at ensuring the viability of the intangible cultural heritage, including the identification, documentation, research, preservation, protection, promotion, enhancement, transmission, particularly through formal and nonformal education, as well as revitalization of the various aspects of such heritage.

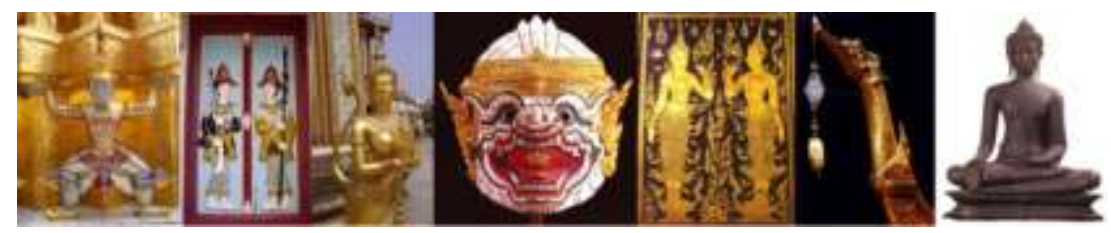

Fig. 3: "Chang Sip Mu’s Arts”

The Chang Sip Mu or the Department of the Ten Crafts originally derived from King Rama V, according to a poem written by Prince Pradit Worakan who was as a chief of this department at that time. There were originally 13 different categories: drawers, paper-makers, carvers, modelers, sculptors, plasterers, lacquerers, metal beaters, turners, moulders, wood-carvers, engravers and carpenters.

The meaning of Chang Sip Mu: "Chang" is a craftsman, "Sip" is not the number of 10 in Thai but that is from Sanskrit, "Sippa" means Arts which is similar to "Silpa" in Pali. "Mu" is a group so all of these are clearly identify the grouping of craftsmen.

Before the Chang Sip Mu (AOT, 1997) was officially working and directly in charge of creating objects of art in response to the King's wishes, the king did not reserve any one of them to serve him exclusively. He intended to recruit craftsmen of different types to be the prime force of the country in building royal palaces, royal regalia, royal vehicles, religious structures, places of worship, necessities for Buddhist monks and various public places. The King considered that it was his duty to contribute to the country and uphold Buddhism. He acted as a patron to various craftsmen, enabling them to contribute to the nation and the monarchy on a continual basis.

The Curriculum of Royal Traditional Thai Crafts School for Men is yearly education, so the adults who want to apply for have to attend the class for a year. There are 6 main major subjects (Wicha) such as mural painting (Wicha Chang Kien), modeler (Wicha Chang Pan), wood-carvers (Wicha Chang Kae Salak Mai), plasterers (Wicha Chang Hua Kone), gilded black lacquer (Wicha Chang Lai Rod Nam) and mother-of-pearl inlay (Wicha Chang Pradab Mook). 


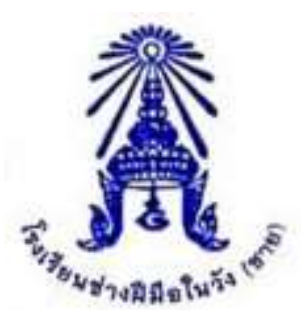

Fig. 4: "The Royal Traditional School's Emblem"

The application could ask for the applicants' qualifications, all applicants have to pass the entrance examination in the both of theoretical and practical and also need to get an interview by specialist teachers. The qualifications will ask for Thai people who are male and female in the age from 15 years old, graduated at least from Mathayomsuksa 3 (or Grade 9) and who are interested in Royal Thai Arts. The application will be yearly between February to the beginning of April and the examination will be in the middle of April. The school asks for a fee from the students about 3,260 Baht for a yearly tuition fee.

The Curriculum is 1,000 hours a year so it is week day studying. There are 3 categories of subjects:

(1) Major Subject is for 800 hours; the students must to study about 800 hours and select only 1 major such as Mural Painting, Modeler, Wood-carvers, Plasterers, Gilded Black Lacquer and Mother-ofPearl Inlay.

(2) 4 Fundamental Career Subjects is for 100 hours: Royal Music and Rites, Drawing, Basic Arts Element and Arts History.

(3) Elective Subject is for 100 hours which the students will select only 1 subject: Lacquer, Banana Plant Carver, Water painting and Pottery.

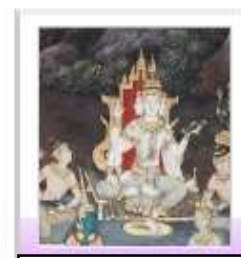

Mural Painting

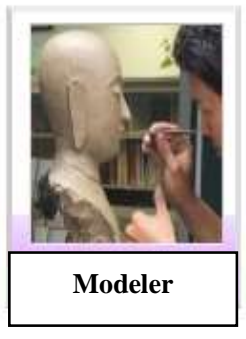

Modeler

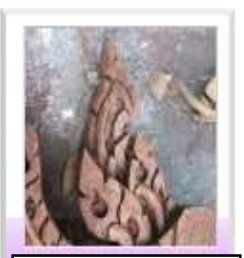

Wood-carvers

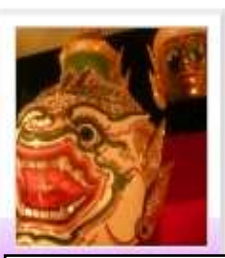

Plasterers

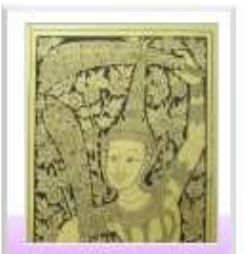

Gilded Black Lacquer

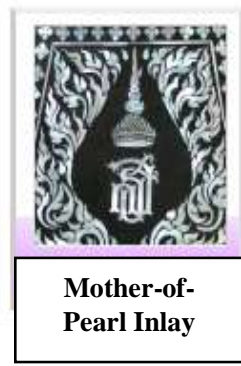

Fig. 5: "Major Subjects"

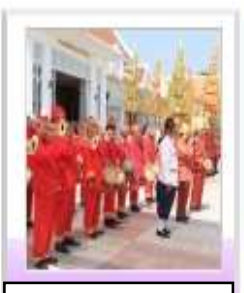

Royal Music and Rites
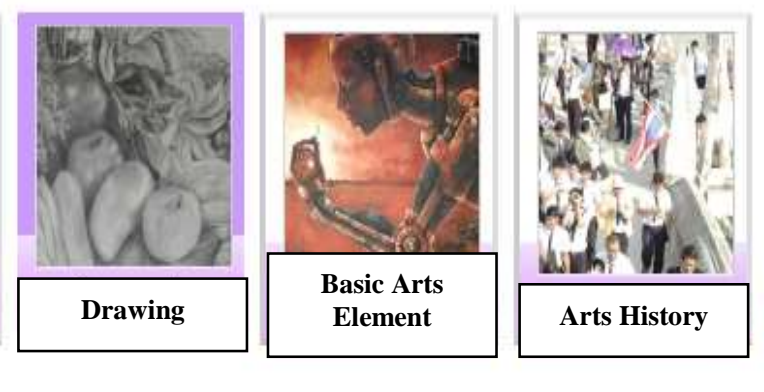

Fig. 6: "Fundamental Career Subjects" 

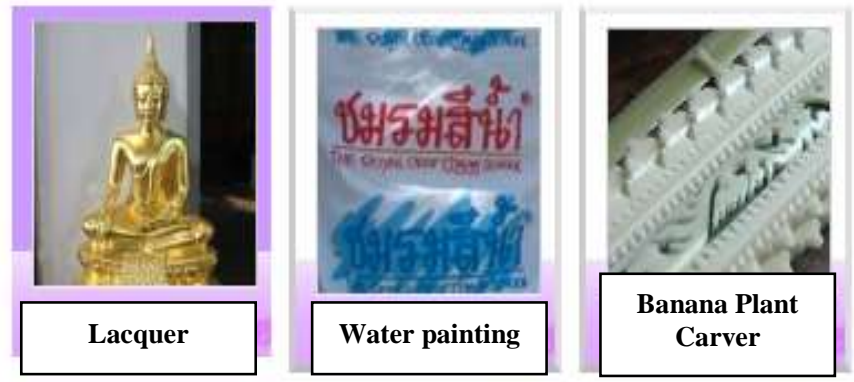

Fig. 7: "Elective Subjects"

The Characteristic of each major:

Mural Painting: To study about drawing, painting, hand-drawing, background drawing, Thai Buddhist style drawing and Thai drawing. Moreover, the students will know about how to prepare the Royal Traditional colors. Modeler: To study about sculpturing the models. How to prepare the tools and mix traditional and modern limes or clays. The techniques of stucco and fresco.

Wood-carvers: To study about the kinds of woods for Royal Traditions. How to prepare the tools. The techniques of carving.

Plasterers: To study about the kinds of Hua Kone (Plaster Heads of the story of Ramayana) and Royal Hua Kone. The techniques of stucco, fresco, drawing and painting. how to prepare the Royal Traditional colors.

Gilded Black Lacquer: To study about the kinds of Black Lacquer, Arts in Gilded and gold leaves. The techniques of its arts. How to prepare the tools.

Mother-of-Pearl Inlay: To study about the kinds of shell and lacquer. The techniques of its arts. How to prepare the tools.

\subsection{Methodology}

1. Documentary Research by searching some books, articles or documents that concerned on the related topics for the understandings of its histories, contents, definitions, theories and the others that support this study. 2. Studying by Anthropological Fieldwork, it was to observe, make a good relationship between researcher and stakeholders such as teachers, students and school administrative and participate some activities with them.

2.1) Informal Interview is for good relationship between researcher and teachers, students and administrative for Key Informants that answers the objectives.

2.2) In-depth Interview uses the interview form that is the opened questions which the interviewers can give the answer by their experience and knowledge. The interview form features;

Part 1: General Information about interviewer

Part 2: History of Royal Traditional Thai Crafts School for Male

Part 3: Cultural Knowledge Management of Great Traditional Culture such as curriculum, cultures and rites and believes

Part 4: Adaptation of themselves for nowadays

2.3) Population: There are 33 people;

- 3 persons from teachers and administrative

- 30 students

2.4) Participant Observation: this is to observe and participate with some activities such as drawing or painting.

3. Analyzing all the results, summary and discussion.

\subsection{Result}

The findings indicated that this school is located in the Grand Palace. The people who contact to this school must wear formal uniform and also must be mature for the place and the officers as their respectful teachers. There are some soldiers to check your dress code before stepping in the palace. The contact must be before follow the security policy. The name of this school focuses on the Male school but at the moment, it is also for 
female. However, they do have female school but that is for only female. Moreover, they are not allowed men to go in the area of the female school. There are 2 floors of this building with the wooden floor on the top floor. There is an Arts Gallery in the middle of the first floor. This school provides the rooms for each major and the teachers are in each classroom to teach and coach the students.

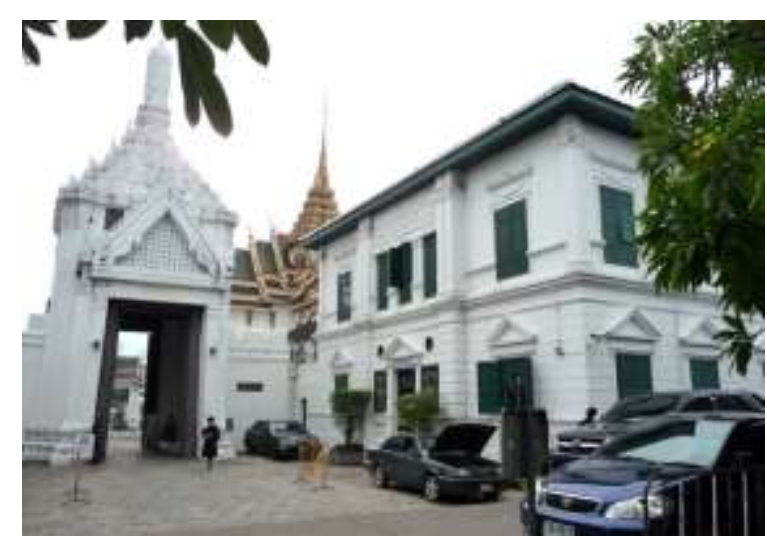

Fig. 8: "Utestaksina Building"

All the teachers and students must wear uniforms so the teachers are wearing Thai govern uniforms and students must wear white shirt and dark pants for male and skirts for female.

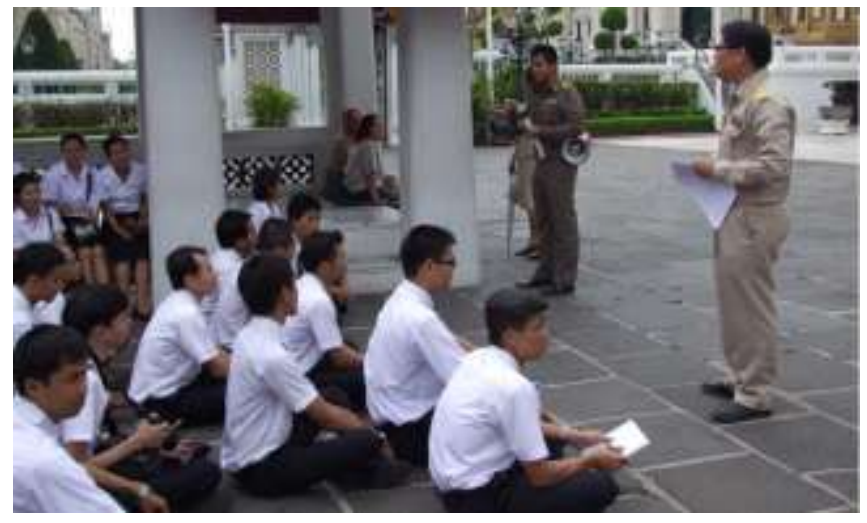

Fig. 9: "Teacher and Student's Uniforms"

The relationship between teachers and students, I could see how the students respect teachers politely. The teachers coach the students with soft-hearted and helpful. Some students are older than teachers; the students are also showing their respect to the teachers.

From the interview, I found that all the teachers are not only teaching but they are also doing the fixing duties all around the Grand Palace. For the history of this school all the teachers could tell that at the settlement of the school, they only asked Sip Mu craftsmen to be teachers so all those teachers needed to give more time to work and the curriculum did not clear. The craftsmen who were free would teach and the others who were busy would not to teach so they needed to switch by scheduling. The reason that they would like to teach because of they loved to give their intellectual knowledge to new generations with kindness. The teaching must follow Royal Tradition that all the students needed to surrender themselves as a holy ceremony called "Krob" or "Prasita- Prasatana" so the teacher would hold student's hand for the first drawing. For daily, the students need to worship before studying. The worship has 3 steps; Firstly is to respect the threefold refuge of Buddhism, secondly is for Brahman - Hindu gods and angles such as three-formed (Brahma, Siva and Vishnu) and Ganesha. Lastly, to respect the King, Monarchy and teachers. This activity is to instruct the students to respect their teachers.

The adaptation of the materials, some materials that they used for long time were changed because of they were hard to find and some were expensive so the teachers with some students helped to create and search for some materials that they could use and they did not damage the Royal Tradition. For some materials such as 
paper, before they must use paper that made from the fibers of Streblus Asper but now they are using normal A3 paper that they can find in the general but the teacher would guild the students to prepare for only the quality paper and the brands of paper. For colors, normally they must color by natural color that the Royal painter must prepare by themselves. Some of colors such as Black is from coal so now they can use the black color that the students can find from supermarket.

2.4 Summary and Discussion

It could be found that the school is trying to spread the Great Tradition as a Royal Tradition to the nationwide. The students must get experience, value, norm and both of Tacit and Explicit Knowledge from their teachers.

From the theory, this school transmitted the knowledge from learning by doing so the teachers would do for the student first then teacher would check and coach. The Knowledge Spiral of this school is

1) Socialization: the teacher and student shared their experience about the techniques and importantly they shared the experience of substituted materials and they tried to develop it.

2) Externalization: they are some books that talked about Chang Sip Mu. However, those books were written by the craftsmen, not students and also the techniques did not appear in the books.

3) Internalization: when the teachers and students share their knowledge by doing so the students were always jotting on their notebooks.

4) Combination: it was only the sharing of materials and techniques but it was not creating new arts.

Cultural Knowledge Management found that

- Identifying: this school separated 6 majors of learning and so they must learn only one major in a year.

- Creating: the teachers and students shared their knowledge about materials and created by their concrete experience and consulted the teacher

- Exchanging: the exchanging of knowledge normally it was one way communication from teacher to student or student to student so I found in the class the teacher would do for an example first then the student needed to copy and the teacher would coach them. For student to student, I could found there was a small exhibition that shown the creative products of senior students.

- Collecting: the teachers collected the creative products each year then shown into the exhibition.

- Using: the students will use this skill for their business in the future so some of them will have their own businesses.

- Accessing: the students accessed by teachers' coaching and the school sometimes brought them to look the Arts outside the school.

In conclusion, Her Royal Highness Princess Maha Chakri Sirindhorn saw that the Royal Tradition was only for the royal family and as days go by this culture almost lost so she had thought to spread this to nationwide to save the Royal Tradition's Life. In the other hand, it spread the great tradition to little tradition. At the beginning, this learning in the past was a memorization study because the teachers had 2 jobs as a teacher and a restorer so the students need to take more than 1 year to learn and the restoration was to serve only the King but at the moment, this vision is moving to be a modern step of learning because the students do not have more time to study and also the school needs to be qualified by Ministry of Education so the teaching management needs to be system and make a shortcut for a year educating and it also was called "Sacred Learning" because this school needed to pray before studying, it focused on obligation and gratitude of the royal family so the students would not have any questions or innovate the new things out off what they had learnt and they just thought and surrendered to this school as it was a tradition or school's identity. However for Arts study is also difficult to manage because the Arts are the practical skills so the students need more time to practice. Although, the school carries out as a traditional education but practically it is impossible to be authentic management because of some factors such as time, rare and cost of materials and educational atmosphere. Especially, the educational atmosphere that in the past it was informal education which students needed to study and helped the teachers to restore and build. Arts Management of this school is a formal and traditional style so it is a characteristic of this school that makes this school different from universities and other schools. For sustainability study emphasizes that the tradition is Thainess to keep for the authenticity of national heritage.

The knowledge management found that the teachers and students shared their knowledge but I could see it was in tradition for creating the arts but for materials clearly could see so other teachers and students would discuss and tried to do it until it was satisfied. 


\section{Acknowledgements}

Thank you very much for this program that provided me to have a space to write and also all my teachers and colleagues that helped me.

\section{References}

[1] N. Ikujiro and T. H., The knowledge-creating company. New York, U.S.A.: Oxford University Press, 1995.

[2] N. Kasidesh, A Management of Intagible Cultural Heritage: A Case Study of Saba Bon in Phrapradaeng District Samutprakan Provice. Bangkok, Thailand: Thammasat University, 2014.

[3] P. Chulatat, Chang Sip Mu. Bangkok, Thailand: Airports of Thailand Public Company Limited (AOT), 1997, pp. 1 15.

[4] P. Michael and N. Ikujiro, The Knowledge Creating Company. Boston, U.S.A.: Harvard Business School Press, 1998.

[5] T. Devenport and L. Prusak, Working Knowledge: New Organization Manage What They Know. Boston, U.S.A.: Harvard Business School Press, 1998.

[6] UNESCO, CONVENTION OF THE INTANGIBLE CULTURAL HERITAGE. Paris, France: 2003, pp. 2-3.

[7] National Intangible Cultural Heritage Registration Manual, $1^{\text {st }}$ ed., Department of Cultural Promotion, The War Veterans Organization of Thailand Under Royal Patronage of His Majesty the King Office of Printing Mill, Bangkok, 2015, pp. 1-16.

[8] Department of Ten crafts. (September 2016). Chang Sip Mu. [Online]. Available: http://changsipmu.com/eng/eng_index.html

[9] K. Michael. (September 2016). What is KM? Knowledge Management Explained. [Online]. Available: http://www.kmworld.com/Articles/Editorial/What-Is-.../What-is-KM-Knowledge-Management-Explained-82405.aspx

[10] Royal Traditional Thai Crafts School for Male. (September 2016). Royal Traditional Thai Crafts School for Male. [Online]. Available: http://www.rcmsc.com/index.html 